\title{
Molecular Characterization of Actinomyhcin D Producing Streptomyces Strain Isolated from Soil Samples
}

\begin{abstract}
Department of Pharmacy, University of Rajshahi, Rajshahi-6205, Bangladesh
Abstract

The taxonomic position of an actinomycete strain, MARS-17 has been examined in this present study. Based on the morphological, biochemical and cultural characteristics, the strain was identified as a species of genus Streptomyces. It formed light brownish gray aerial mycelia and produced yellow-colored diffusible pigments. The 16S rRNA gene of this strain was sequenced and phylogenetic analysis using the sequence showed that the strain is most closely related to Streptomyces parvulus AB184326 (99.6\%) and Streptomyces malachitospinus AB249954 (99.0\%). On the basis of the 16S rDNA sequence and phenotypic characteristics, the strain was identified as a new type strain of Streptomyces parvulus. The strain produced a single antimicrobial compound in the Czapek-dox fermentation media which was indentified as actinomycin D from its spectral data.
\end{abstract}

Key words: Actinomycetes, bioactive secondary metabolites, Streptomyces parvulus, actinomycin D.

\section{Introduction}

Streptomyces is the largest genus of actinomycetes and constitute $50 \%$ of the total population of soil actinomycetes. They are gram-positive, aerobic bacteria with high DNA $\mathrm{G}+\mathrm{C}$ contents and exhibit the characteristic morphology of a vegetative substrate mycelium and a spore-forming aerial mycelium (Angert, 2005). They are well known for producing a variety of bioactive secondary metabolites including antibiotics, immunomodulators, anticancer drugs, antiviral drugs, herbicides, and insecticides (Vining, 1990; Sanglier et al., 1993; Berdy, 1995). About 75\% of commercially produced and medically useful antibiotics have been isolated from these bacteria (Miyadoh, 1993). Due to the technical improvement of screening methods for bioactive compounds from natural sources, thousands of compounds have been discovered and among them majority were isolated from microbes (Demain and Sanchez, 2009). From the 22,500 biologically active compounds that have been obtained form microbes, $45 \%$ are produced by actinomycetes (mainly Streptomyces), 38\% by fungi, and 17\% by unicellular bacteria (Berdy, 2005).

Historically the isolates of microorganisms producing bioactive metabolites were identified based on their accurate description of the morphologic and phenotypic properties keeping standard references such as Bergey's Manual of Systematic Bacteriology or the Manual of Clinical Microbiology to summarize the characteristics of the isolated microorganisms. These traditional methods for identification of bacteria, including actinomycetes, could not produce perfect match and sometimes led to wrong identification (Clarridge, 2004). Moreover, identification of bacteria using these traditional methods are time consuming and laborious. In the late 1980s, a new standard for identification of bacteria as well as other microorganisms was developed which was based on the sequence of the genes that code for 16S rRNA (also called small subunit). The $16 \mathrm{~S}$ rDNA sequences are used to compare the percentage of similarity of the target strain with the sequences of other strains deposited in the GenBank/EMBL database and to construct phylogenetic tree which helps in the determination of evolutionary development. 16S rRNA gene sequences provide correct identification and taxonomic name assignment (Woese, 1987).

The objective of this present study was to characterize the soil bacterial isolate MARS-17 using morphological, cultural, physiological, biochemical characteristics as well as from the phylogenetic analysis using complete 16S rDNA sequence.

\section{Materials and Methods}

Collection of the organism: The strain MARS-17 was isolated from a soil sample collected from Rajshahi, Bangladesh using Starch-casein-agar-nitrate medium, a selective isolation medium of actinomycetes. The

Correspondence to: Md. Anwar Ul Islam, E-mail address: profanwarulislam@yahoo.com 
organism was found to possess very good broad-spectrum activity as determined by cross-streaking method and selected for characterization and secondary metabolite production. The culture was maintained in Czapek-dox acidic agar slants and by $20 \% \mathrm{w} / \mathrm{v}$ glycerol stock.

Morphological, physiological and biochemical characterization: The color of the aerial mycelia and pigment production by the isolate were determined on yeast-extract-glucose agar plates after 7 days of incubation at $32^{\circ} \mathrm{C}$. For determination of the morphological and cultural characteristics, the organism was cultivated on Yeast-extract-malt extract agar (ISP2), Oatmeal agar (ISP3), Inorganic salt-starch agar (ISP4), Glycerol-asparagine agar (ISP5), and Yeast-extract glucose agar media. The physiological characteristics were examined by cultivation on ISP-6 media for melanoid production, coagulation of milk, liquefaction of gelatin, peptonization of milk, hydrolysis of starch, decomposition of cellulose, nitrate reduction, and $\mathrm{NaCl}$ tolerance. The use of carbohydrates was studied by using the medium ISP-9, containing 8 different carbon sources at a concentration of $1 \%$ as only carbon source. Microscopic observations were made to observe the colonial morphology.

Preparation of genomic DNA: A single colony was isolated from the agar plate and the isolated colony was dispersed in $500 \mu$ of saline-EDTA buffer $(\mathrm{NaCl} 150 \mathrm{mM}$; EDTA $10 \mathrm{mM}$; pH 8.2) and incubated for $1 \mathrm{hr}$ at $37^{\circ} \mathrm{C} .10$ $\mu \mathrm{l}$ of lysozyme solution $(5 \mathrm{mg} / \mathrm{ml}), 5 \mu \mathrm{l}$ of proteinase $\mathrm{K}$ solution $(15 \mathrm{mg} / \mathrm{ml})$ and $10 \mu \mathrm{l}$ SDS solutions (25\%) were added and incubated for 30 minutes at 55C. Lysate was extracted using equal volume of water saturated phenol chloroform mixture and purified by ethanol precipitation method and dissolved in nano pure sterile water $(60 \mu \mathrm{l})$.

16S rRNA gene amplification and sequencing: The 16S rRNA gene of isolates was amplified from purified DNA by using the primers 5'-AGAGTTTGATCCT GGCTCAG-3' and 5'- GGTTACCTTGTTACGACTT -3' (Weisburg et al, 1991) and AmpliTaq gold polymerase (Applied biosystems, Roche Molecular Systems, Inc., NJ, and USA). The PCR conditions were as follows: an initial denaturation at $95^{\circ} \mathrm{C}$ for 6 min, followed by 35 cycles of denaturation at $95^{\circ} \mathrm{C}$ for $1 \mathrm{~min}$, annealing at $57^{\circ} \mathrm{C}$ for 1 min, and extension at $72^{\circ} \mathrm{C}$ for 2 min, with a final extension at 72 for $10 \mathrm{~min}$. Then the amplified PCR product was electrophoresed in agarose gel, purified with
QIAquick Gel Extraction Kit (Qiagen, Germany), and ligated into the pTAC-1 cloning vector (BioDynamic Laboratories Inc, Tokyo, Japan). Sequencing was done with primers M13 BDFw and M13 BDRev using a ABI prism BigDye Terminator v3.1 Cycle Sequencing kit (Applied Bioscience, CA, USA). The sequences were obtained with a model 3100 Avant Genetic Analyzer automated sequencer (Applied Biosystems, USA).

Phylogenetic analysis: Phylogenetic and molecular evolutionary analyses were conducted using MEGA version (Tamura et al., 2007) with two treeing algorithms, maximum-parsimony (Kluge and Farris, 1969) and neighbour-joining (Saitou and Nei, 1987) methods using bootstrapping with 1000 replicates. The DNA sequence of 16S rRNA gene of strain MARS-17 was submitted to the GenBank under the accession number GQ451836.

\section{Results and Discussion}

The morphological, cultural, physiological and biochemical characteristics of the strain MARS-17 were studied extensively. The aerial mass color was brownishgray after 7 days incubation on yeast-extract-glucose agar media (Figure 1). The isolate exhibited morphology of typical Streptomyces; the colonies were slow growing, aerobic, glabrous or chalky and folded. In addition, it possessed an earthy odor. Aerial mycelia branched monopodially and formed spiral spore chains. The isolate could grow over a wide range of temperature $\left(20-40^{\circ} \mathrm{C}\right)$ and can utilise D-glucose, D-fructose, lactose, mannitol, inositol, sucrose, D-xylose and L-Rhamnose. It grew abundantly on ISP-2, ISP-4, ISP-5 and yeast-extract glucose agar but moderately on ISP-3, and ISP-6. It could hydrolyse starch, liquefy gelatin, and could reduce nitrate (Tables 1, 2 \& 3). These phenotypic properties were accordance to the Streptomyces species described in the literature (Shirling and Gottlieb, 1966; Shirling and Gottlieb, 1968) and the Bergey's Manual of Systematic Bacteriology (Williams et al., 1943), and was assigned to the genus Streptomyces.

Strain MARS-17 was subjected to 16S rDNA sequencing to reveal its phylogenetic relationships with representative streptomycetes. An almost complete sequence was determined (1,488 nucleotides, GenBank accession number GQ451836). The sequence was then 
compared with the other sequences deposited in GenBank/EMBL/DDBJ database using BLAST. The strain MARS-17 was close to maximum $99.6 \%$ to Streptomyces parvulus AB184326. The phylogenetic tree constructed using 16S rDNA sequence showed that this strain was is very close to the strain of Streptomyces parvulus AB184326 as they form same branch in the tree (Figure 2). Along with the phenotypic properties the genetic relatedness and phylogenetic development, we concluded that the strain is a new type strain of Streptomyces parvulus with $0.4 \%$ dissimilarity with the reported strains of this bacterium

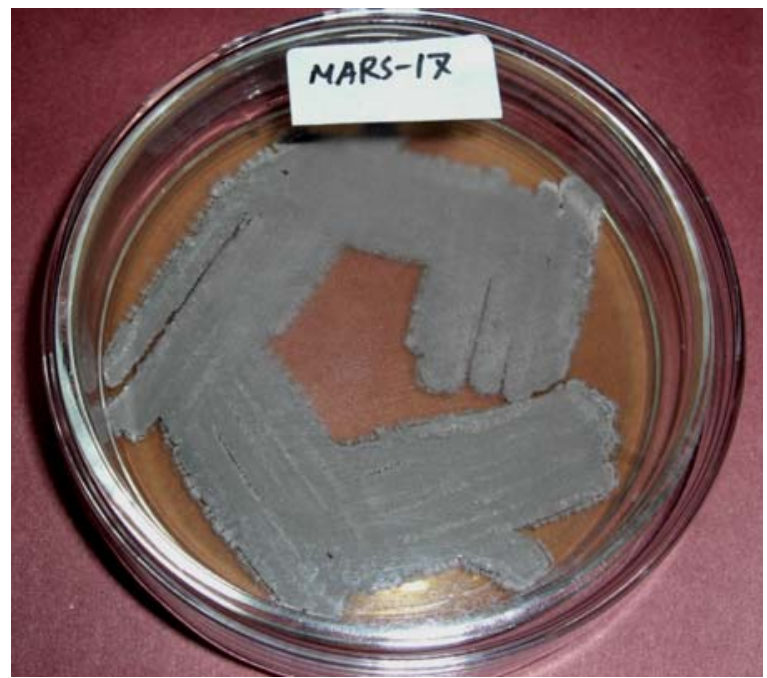

A

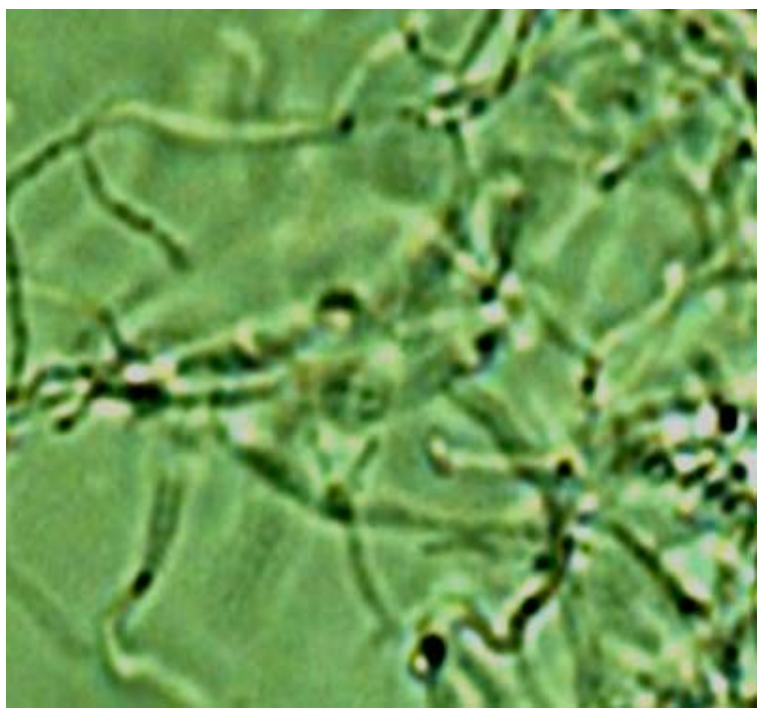

B

Figure 1. A. Aerial mycelial view of MARS-17

B. Microscopic view of MARS-17 at magnification $\times 300$, (yeast extractglucose-agar media, 7 days old culture)
Table 1. Cultural characteristics of MARS-17 (Incubation period: 14 days, Temp: $30^{\circ} \mathrm{C}$.)

\begin{tabular}{lcccc}
\hline Medium & Growth & $\begin{array}{c}\text { Aerial } \\
\text { mycelium }\end{array}$ & $\begin{array}{c}\text { Reverse side } \\
\text { substrate } \\
\text { mycelium }\end{array}$ & $\begin{array}{c}\text { Diffusible } \\
\text { pigment }\end{array}$ \\
\hline $\begin{array}{l}\text { Yeast-extract-malt } \\
\text { extract agar (ISP 2) } \\
\text { Oatmeal agar (ISP 3) }\end{array}$ & Abundant & $\begin{array}{c}\text { Grayish } \\
\text { brown }\end{array}$ & Grayish yellow & None \\
$\begin{array}{l}\text { Inorganic salt-starch agar } \\
\text { (ISP 4) }\end{array}$ & Abundant & $\begin{array}{c}\text { Grayish } \\
\text { brown }\end{array}$ & $\begin{array}{c}\text { Yellowish } \\
\text { white }\end{array}$ & None \\
$\begin{array}{l}\text { Glycerol-asparagine agar } \\
\text { (ISP5) }\end{array}$ & Abundant & $\begin{array}{c}\text { Grayish yellow } \\
\text { Brownish } \\
\text { gray }\end{array}$ & Yellowish & None \\
$\begin{array}{l}\text { Peptone-yeast-extract- } \\
\text { iron agar (ISP 6) }\end{array}$ & Moderate & $\begin{array}{c}\text { None } \\
\text { Nutrient agar }\end{array}$ & Light Yellow & None \\
$\begin{array}{llccl}\text { Yeast-extract glucose } \\
\text { agar }\end{array}$ & Abundant & $\begin{array}{c}\text { Grayish } \\
\text { brown }\end{array}$ & Grayish yellow & Moderate \\
\hline
\end{tabular}

Table 2. Physiological characteristics of the strain MARS-17.

\begin{tabular}{lc}
\hline Properties & Results \\
\hline Temperature range for growth & $20-40^{\circ} \mathrm{C}$ \\
Optimum temperature for growth & $26-34^{\circ} \mathrm{C}$ \\
Liquefaction of gelatin & + \\
Coagulation of milk & - \\
Peptonization of milk & + \\
Hydrolysis of starch & ++ \\
Melanoid production & - \\
Decomposition of cellulose & - \\
Nitrate reduction & ++ \\
NaCl tolerance & $0-2 \%$ \\
Keratolytic activity & -
\end{tabular}

The '++' sign indicates positive, '+' sign weakly positive and ‘sign negative

Table 3. Utilization of carbon sources by the strain MARS-17.

\begin{tabular}{lcc}
\hline Carbon source & Utilization & $\begin{array}{c}\text { Production of } \\
\text { yellow pigments }\end{array}$ \\
\hline D-Glucose & + & +++ \\
D-fructose & + & ++ \\
Lactose & + & ++ \\
Mannitol & + & + \\
Inositol & + & + \\
Sucrose & + & +++ \\
D-Xylose & + & ++ \\
L-Rhamnose & + & ++ \\
No addition & - & - \\
\hline
\end{tabular}

The sign '+++' indicates abundant production, '++' sign moderate and '十' poor production 


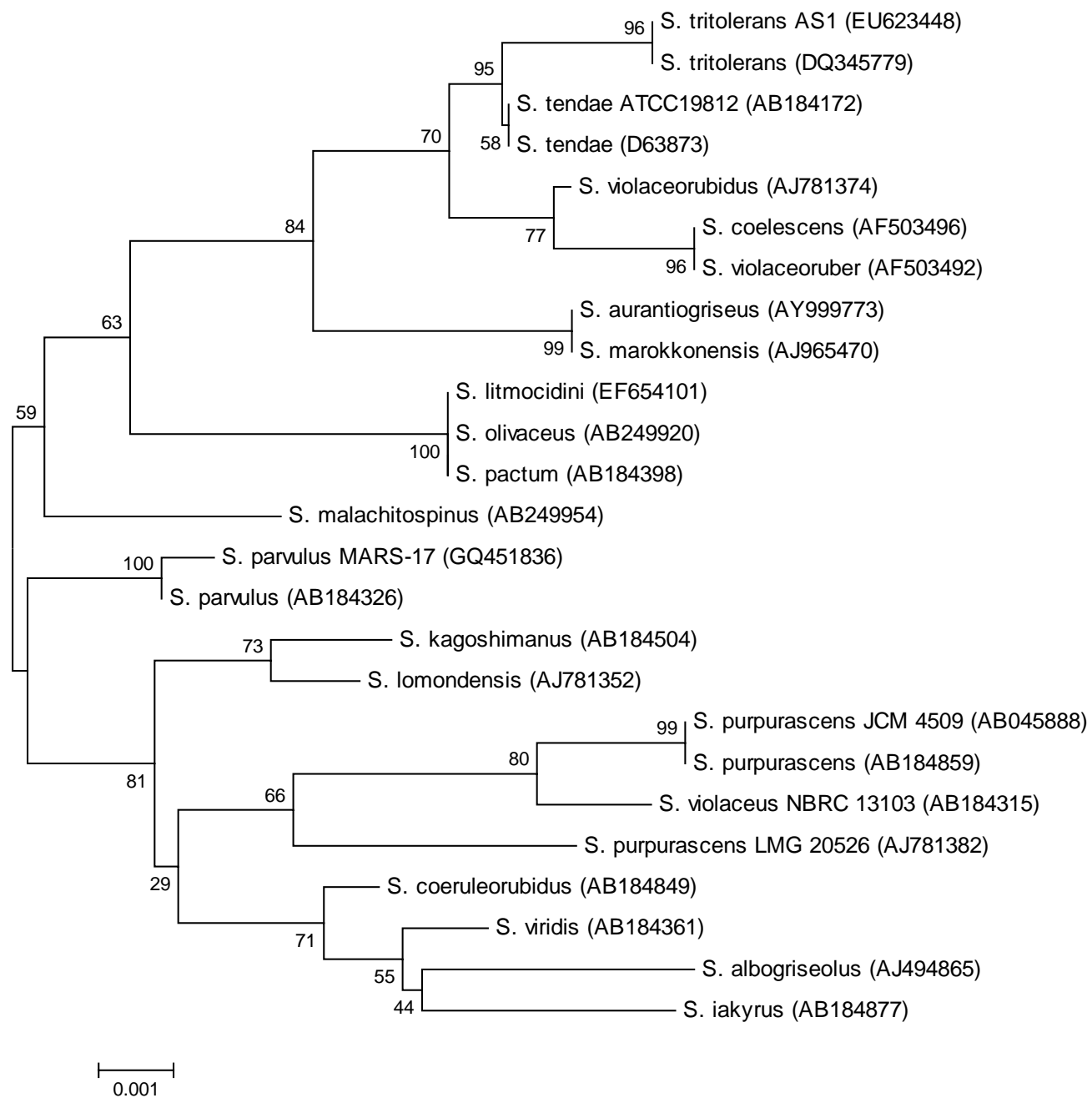

Figure 2. Dendrogram showing the relationships between Streptomyces sp. Starin MARS-17 and other Streptomyces sp. The rooted tree was constructed using the neighbor-joining method. The scale bar indicates a 0.001 substitution per nucleotide position

A highly active antibacterial compound designated as AR-1a was purified from the ethyl acetate extract of Czapek-dox acidic broth. The compound had a yield of 18 $\mathrm{mg} / \mathrm{L}$ of broth. It was yellow-colored and soluble in methanol, ethyl acetate and DMSO. The molecular weight of the compound was determined by mass spectrum. The molecular ion $\mathrm{M}(+)$ peak appeared at $\mathrm{m} / \mathrm{z}$ ratio 1257 which correspond to the molecular formula $\mathrm{C}_{62} \mathrm{H}_{86} \mathrm{~N}_{12} \mathrm{O}_{16}$. The structure of this compound was confirmed as actinomycin $\mathrm{D}$ by analysis of its ${ }^{1} \mathrm{H}-\mathrm{NMR},{ }^{13} \mathrm{C}-\mathrm{NMR}$ spectral data (Rahman et al., 2010).

\section{Conclusion}

Under this project we isolated thirty actinomycetes from five soil samples collected from northern districts of Bangladesh. Among them sixteen isolates (53.3\%) were found to have moderate to high activity against four grampositive and four gram-negative bacteria (Rahman et al, 2011). The isolate MARS-17 exhibited highest activity against the test bacteria, thus we selected it to produce metabolites in non-optimized fermentation media and to characterize up to species level. The small-scale liquid fermentation yielded a single bioactive compound, actinomycin D. Streptomyces parvulus is a well-known producer of actinomycin $\mathrm{D}$, an antitumor drug used clinically to treat several malignant tumors. 
These findings led us to conclude that probably most of the highly active antibiotic producing microorganisms have been already discovered. So, more effort should be given to investigate the poorly investigated biotopes like marine ecosystems for new species of actinomycetes producing novel bioactive metabolites. Moreover, the moderately active isolates which are usually neglected during the screening study demand more investigation using optimized culture conditions.

\section{Acknowledgements}

The authors thank to Professor Dr. Makoto Ojika, Nagoya University, Japan for providing with the spectral data of the compound, and to Professor Dr. M. Ekramul Haque, University of Rajshahi for evaluation of the spectral data.

\section{References}

Angert, E. R. 2005. Alternatives to binary fission in bacteria. Nat. Rev. Microbiol., 3, 214-224.

Berdy, J. 1995. Are Actinomycetes exhausted as a source of secondarymetabolites? Proceedings of the $9^{\text {th }}$ Symposium Actinomycetes, 13-34.

Berdy, J. 2005. Bioactive microbial metabolites: a personal view. J. Antibiotics, 58, 1-26.

Clarridge, J. E. 2004. Impact of 16S rRNA Gene sequence analysis for identification of bacteria on clinical microbiology and infectious diseases, Clin. Microbiol. Rev., 17, 840-862.

Demain, A.L., Sanchez, S. 2009. Microbial drug discovery: 80 years of progress. J. Antibiotics, 62, 5-16.

Kluge, A. G., and Farris, J. S. 1969. Quantitative phyletics and the evolution of anurans. Syst. Zool., 18, 1-32.

Miyadoh, S. 1993. Research on antibiotic screening in Japan overthe last decade: a producing microorganisms approach. Actinomycetologica, 9, 100-106.
Rahman, M.A., Islam, M.Z., and Islam, M.A. 2011. Antibacterial activities of actinomycete isolates collected from soils of Rajshahi, Bangladesh. Biotechn. Res. Int., doi:10.4061/ 2011/857925.

Rahman, M.A., Islam, M.Z., Khondkar, P., and Islam, M.A. 2010. Characterization and antimicrobial activities of a polypeptide antibiotic isolated from a new strain of Streptomyces parvulus. Bangladesh Pharm. J., 13, 14-16.

Saitou, N. and Nei, M. 1987. The neighbor-joining method: a new method for reconstructing phylogenetic trees. Mol. Biol. Evol., 4, 406-425.

Sanglier, J.J., Haag, H., Huck, T.A., and Fehr, T. 1993. Novel bioactive compounds from actinomycetes: a short review (1988-1992). Res. Microbiol., 144, 633-642.

Shirling, E.B. and Gottlieb, D. 1968. Cooperative description of type culture of Streptomyces II. species description from first study. Int. J. Syst. Bacteriology, 69-189.

Shirling, E.B. and Gottlieb, D. 1966. Methods of characterization of Streptomyces species. Int. J. Syst. Bacteriology, 16, 313340.

Tamura, K., Dudley, J., Nei, M., and Kumar, S. 2007. MEGA 4: molecular evolutionary genetics analysis (MEGA) software version 4.0. Mol. Biol. Evol., 24, 1596-1599.

Vining, L.C. 1990. Functions of secondary metabolites. Annual Review of Microbiol., 44, 395-427.

Weisburg, W.G., Barns, S.M., Pelletier, D.A. and Lane, D.J. 1991. 16S rDNA amplification for phylogenetic study. $J$. Bacteriol., 173, 697-703.

Williams, S.T., Goodfellow, M. and Alderson, G. Genus Streptomyces Waskman and Henrici 1943, 339AL. Bergey’s Manual of Systematic Bacteriology, 4, 2452-2492.

Woese, C.R. 1987. Bacterial evolution. Microbiol. Rev., 51, 221271. 